\title{
Pós-Grande Indústria e Neoliberalismo
}

\author{
Post-Large Scale Industry and Neoliberalism
}

ELEUTÉRIO F. S. PRADO ${ }^{1}$

RESUMO: O capitalismo está vindo da fase moderna para a fase pós-moderna da indústria. $\mathrm{Na}$ indústria moderna, como foi dito no Capital, o principal conteúdo material da relação de capital eram os ativos físicos (sistemas de máquinas); na indústria pós-moderna, as principais formas de capital são impressas nos ativos intangíveis (conhecimento científico e tecnologias). Como Marx previu em Grundrisse, agora o capital se apropria não apenas do trabalho vivo, mas também do intelecto geral. Deste ponto de vista, o neoliberalismo e a globalização do capital não são vistos aqui, imediatamente, como resultados da dominação do capital financeiro, mas como expressões da contradição do capital e do trabalho na indústria pós-grande escala.

PALAVRAS-CHAVE: Neoliberalismo; indústria pós-grande escala; totalitarismo; ideologia econômica.

ABSTRACT: Capitalism is coming from the modern industry phase to the post-modern industry phase. In modern industry, as was said in Capital, the main material content of capital relation was physical assets (systems of machines); in post-modern industry, the main forms of capital are impressed on intangible assets (scientific knowledge and technologies). As Marx in Grundrisse previewed it, now capital appropriates not only live labor, but general intellect too. From this point of view, neoliberalism and capital globalization are not viewed here, immediately, as results of financial capital domination, but as expressions of capital and labor contradiction in the post-large scale industry.

KEYWORDS: Neoliberalism; post-large scale industry; totalitarism; economic ideology.

Jel Classification: B51, P16, O34.

\section{INTRODUÇÃO}

Faz-se normalmente nos dias de hoje uma conexão estreita entre neoliberalismo e mundialização do capitalismo (a qual é também chamada, de modo especialmen-

\footnotetext{
${ }^{1}$ Professor do Departamento de Economia, Faculdade de Economia, Administração e Contabilidade da Universidade de São Paulo - FEA/USP, São Paulo - SP, Brasil. E-mail: eleuter@usp.br. Submetido: novembro 2003; aceito: fevereiro 2004.
} 
te superficial, de globalização). Por mundialização entende-se comumente a reconstrução, a unificação do mercado mundial sob a égide do capital internacional e financeiro; por neoliberalismo compreende-se o pensamento político, assim como a prática de governança e de reestruturação do Estado, originado do predomínio do capital financeiro em relação ao capital produtivo, em nível global. Essa visão será aqui criticada até certo ponto. Para apresentá-la de modo sintético será feito uso aqui de uma condensação de idéias que se encontra no livro Economia marxista do capitalismo de Duménil e Lévy. Por mundialização esses autores entendem uma continuidade e uma ruptura no processo histórico de desenvolvimento capitalista:

"A mundialização é um processo muito antigo que Marx havia identificado como uma grande tendência do capitalismo (a construção do mercado mundial). A progressão das trocas, o fluxo dos capitais e a exploração global (do mundo) não são invenções do neoliberalismo. A etapa atual se caracteriza pelo crescimento das operações de troca e dos fluxos internacionais de capitais, a expansão das sociedades multinacionais e um novo papel das instituições financeiras internacionais (Fundo Monetário Internacional, Banco Mundial etc.)." (Duménil e Lévy, 2003: 28-29).

Já para caracterizar o neoliberalismo, Duménil e Lévy se referem a novos modos de funcionamento do capitalismo que decorrem dessa mundialização:

"O neoliberalismo se remete aos novos modos de funcionamento do capitalismo, tanto no centro como na periferia: uma nova disciplina do trabalho e da gestão dos ganhos dos credores e dos acionistas; o recuo das intervenções estatais em matéria de desenvolvimento ou proteção social; o crescimento espetacular das instituições financeiras; a criação de novas relações entre os setores não financeiros e financeiros com vantagens para estes últimos; uma nova atitude favorável às fusões e aquisições; uma grande desregulamentação financeira; um reforço do poder e da autonomia dos bancos centrais cuja ação se concentra na estabilidade dos preços; a determinação de drenar para o centro os recursos da periferia. O neoliberalismo dá novas formas à mundialização, notadamente àquelas da dívida do terceiro mundo e estragos causados pela livre mobilidade dos capitais. A característica principal da fase atual é sua extensão gradual ao conjunto do planeta, sua própria mundialização" (Duménil e Lévy, 2003: 29).

É preciso notar que toda essa caracterização, a qual não deixa de ter o seu interesse para o entendimento da questão, concentra-se em apontar rupturas nas formas fenomenais do capitalismo contemporâneo. Ora, assume-se aqui que as indagações sobre a natureza da mundialização e do neoliberalismo só podem ser esclarecidas investigando as mudanças que estão ocorrendo na base do modo de produção capitalista, ou seja, na forma de subsunção do trabalho ao capital, ou 
ainda, dizendo de outro modo, na disciplina do capital. Não se procura pensar os fenômenos contemporâneos a partir de uma análise da repartição da renda e da riqueza, o que, em última análise, remete-se às lutas de classes, de modo imediato. Diferentemente, procura-se pensá-los a partir de seus fundamentos econômicos estruturais. A questão do modo histórico pelo qual o neoliberalismo se impõe e se espalha no mundo deve ser enfrentada apenas num segundo momento - o que, aliás, não é feito neste texto.

Sustenta-se aqui que o capitalismo está saindo da etapa de grande indústria para passar para a fase da pós-grande indústria e que a matéria privilegiada da relação de capital - este, lembrando, só existe por meio de suas formas - está se modificando. Se antes a matéria por excelência do capital era o sistema de máquinas, agora vem a ser o que Marx denominava de inteligência coletiva (general intelect) - ou seja, uma força produtiva social inerentemente desterritorializada que pode estar, em princípio, em todos lugares ao mesmo tempo. Se antes o capital produtivo aparecia, sobretudo, como ativo físico (máquina, fábrica etc.), agora ele se configura de modo especial como ativo intangível (informação, conhecimento etc.). São diversas as conseqüências dessa transformação do modo de produção: dentre essas, cumpre destacar aqui que o capitalismo se vê, finalmente, como capitalismo ${ }^{2}$. Em particular, ao se considerar o mundo como um todo, ela põe a descoberto o capital como sugador da força de trabalho social, ficando assim comprovadas no nível da aparência as teses da exploração impiedosa e do pauperismo de Marx.

A argumentação aqui desenvolvida vem a ser uma apropriação crítica da tese de Wallerstein segundo a qual, entre 1968 e 1989, ocorreu o colapso do liberalismo (Wallerstein, 2002). Considera-se que essa tese é importante porque aponta para mudança histórica bem fundamental. Ela será apropriada e absorvida neste texto, no entanto, não propriamente como morte do pensamento liberal, mas como sua transformação dialética. $\mathrm{O}$ advento do neoliberalismo não será entendido aqui apenas como o que vem depois do fim do liberalismo, mas como interversão do próprio liberalismo. Após derivar o liberalismo, seguindo Marx, das contradições do próprio capitalismo, procura-se mostrar que é o fundo do liberalismo que aparece no neoliberalismo.

Assim, será necessário mostrar que as raízes do liberalismo encontram-se na contradição entre a aparência e a essência do modo de produção capitalista. Para mostrar a especificidade do neoliberalismo, será preciso distingui-lo de dois momentos anteriores do liberalismo, o liberalismo clássico e o liberalismo social - o qual vem a ser uma mudança do liberalismo que acabou confluindo historicamen-

\footnotetext{
${ }^{2}$ Perry Anderson nota que os defensores da propriedade privada, no passado, evitaram "propor uma ideologia expressamente capitalista", mas que, diferentemente, com a chegada do neoliberalismo, "pela primeira vez na história, o capitalismo se proclama como tal, numa ideologia que anuncia a chegada de um ponto final no desenvolvimento social, uma construção de uma ordem ideal baseada em mercados livres, além da qual qualquer aperfeiçoamento substancial seria inimaginável" (Anderson, 2003: 84 e 87). Ele nada diz, entretanto, sobre as condições materiais históricas que tornaram essa ideologia possível.
} 
te com a social-democracia, originada esta do socialismo. O liberalismo social será entendido como uma primeira negação do pensamento liberal originário ${ }^{3}$.

O neoliberalismo será então considerado como um terceiro momento, constituído por uma segunda negação, ou seja, como aquele em que o liberalismo é negado como liberalismo.

Para desenvolver essa tese será necessário, primeiro, fazer distinção entre três momentos do desenvolvimento do próprio modo de produção: grande indústria competitiva, grande indústria monopolista e pós-grande indústria ${ }^{4}$. Ainda que os períodos históricos característicos dessas formas de disciplina do capital não coincidam exatamente com os períodos históricos característicos das formas indicadas de liberalismo ${ }^{5}$, será estabelecida uma relação lógica entre elas. Procura-se mostrar que a sucessão das formas de liberalismo, assim como das formas de Estado capitalista (clássico, intervencionista e neoliberal) guardam relação - estão aí inscritas como possibilidades - com as formas de subsunção do trabalho ao capital. São possibilidades, aliás, que apenas conseguem se impor, com idas e vindas, por meio de lutas políticas, no curso da história. Não se pretende aqui, pois, explicar a superestrutura a partir da estrutura econômica da sociedade.

Relaciona-se o liberalismo clássico à subsunção real (formal e material) da grande indústria competitiva, o liberalismo social à subsunção real (formal, material e organizacional) da grande indústria monopolista e, finalmente, o neoliberalismo à subsunção real (formal, intelectual e societária) da pós-grande indústria. $\mathrm{O}$ primeiro momento será tratado como o momento da aparência, o segundo será considerado como o momento da essência, e o terceiro será encarado como o momento da interversão em que a contradição aparece.

\footnotetext{
${ }^{3}$ Wallerstein identifica também essa primeira mudança, mas não como negação; em conseqüência, ele apenas poderá enxergar o neoliberalismo, erroneamente, como um retorno: "O que é importante perceber é que esse 'contra-ataque' é uma reversão de estratégia pelas classes privilegiadas, ou ainda um retorno à estratégia do pré-1848, na qual se administrava o descontentamento dos trabalhadores conjugando indiferença e repressão. Após 1848, até 1968, as classes privilegiadas tentaram apaziguar a classe trabalhadora através da instituição do Estado liberal em combinação com doses de concessões econômicas. A estratégia foi politicamente vitoriosa. Elas apenas reverteram essa estratégia quando a conta tornou-se muito alta, o que apenas ocorreu recentemente" (apud Beynon, 2003).

${ }^{4}$ Conforme Dobb, o período histórico da manufatura vai de meados do século XVI ao último quartel do século XVIII, quando então se inicia o período histórico da grande indústria (Dobb, 1983: 15). Por razões que serão aludidas mais à frente, acredita-se aqui que o período da grande indústria termina na década dos anos 70 do século XX, quando então se inicia o período da pós-grande indústria.

${ }^{5} \mathrm{O}$ período de formação do liberalismo clássico vai de meados do século XVIII a meados do século XIX (fisiocracia e economia clássica; Quesnay e Adam Smith são os grandes nomes). O período do liberalismo social vai do final do século XIX até os trinta anos posteriores à Segunda Guerra Mundial (John Stuart Mill e John M. Keynes). A partir de então se tem o período do neoliberalismo (F. A. Hayek e L. Von Mises). A predominância dessas ideologias tem, entretanto, uma história muito complicada. Ver, por exemplo, Polanyi (1980) e Yergin e Stanislaw (2002).
} 


\section{TRÊS MOMENTOS DO CAPITALISMO}

É bem sabido que Marx distingue a subsunção meramente formal e a subsunção real do trabalho ao capital. Ora, para esse autor, trabalho é atividade orientada para a realização de um fim particular; já capital é trabalho morto que suga o trabalho vivo, valor que se valoriza, e que, portanto, tem a si mesmo como um fim geral, único e absoluto. Subsunção, pois, significa subsunção do particular ao geral, do plural ao unitário e do relativo ao absoluto.

Para compreender toda essa questão, pois, é preciso começar pelo conceito de processo de trabalho, cujos elementos são o próprio trabalho, o seu objeto e os seus meios. O objeto de trabalho é simplesmente a matéria natural (terra), seja na forma bruta seja numa forma já modificada pela mediação do próprio trabalho. Os meios de trabalho são objetos especiais que conduzem a atividade, potenciam a força produtiva do trabalho e que os trabalhadores interpõem entre si mesmos e os objetos de trabalho. Ao processo de trabalho como tal, pois, é inerente a determinação subjetiva posta pelo trabalhador, já que o objeto moldado por sua atividade precisa ter existido antes em sua imaginação, de um modo ideal. Não pode haver, em conseqüência, subordinação do trabalho a uma potência alienante enquanto este permanecer privado, individual e isolado. Eis que a subsunção do trabalho ao capital apenas pode ocorrer num processo coletivo de trabalho em que a independência, a individualidade e a privacidade do trabalhador lhe são subtraídas. Dizendo de outro modo, a subsunção do trabalho ao capital está em contradição com o próprio processo de trabalho.

Se há, então, subordinação, o processo de trabalho tem de ocorrer no interior de um processo de produção que transcende o interesse, a vontade e a imaginação do trabalhador e que é, sobretudo, ao mesmo tempo, um processo de valorização. O trabalho, agora, produz não apenas um produto que tem "valor de uso, mas uma mercadoria, não só valor de uso, mas valor e não só valor, mas também mais-valia" (Marx, 1983a: 155). O processo de produção capitalista se configura como tal quando o trabalhador passa a trabalhar sob o controle do capitalista por meio da venda temporária de sua força de trabalho. Este último detém quase todas as condições necessárias para que a produção se realize: possui os meios de produção, as matérias-primas e os instrumentos de trabalho, assim como o dinheiro que pode comprar a força de trabalho, dinheiro este que o trabalhador recebe como salário com o qual compra a própria sobrevivência em sociedade. $\mathrm{O}$ trabalho, agora, pertence ao movimento de um processo de produção administrado pelo capitalista. Este o controla como um todo, assim como o destino do produto, o qual lhe pertence como mercadoria. Entretanto, ele só não pode possuir o próprio trabalhador que, em potência ou efetivamente, continua sempre tendo fins que lhe são adversos.

$\mathrm{Na}$ origem do novo modo de produção, no entanto, o agente de sua constituição histórica, o capitalista, apenas podia contratar a força de trabalho existente, tal como esta havia se desenvolvido anteriormente. Aqueles que se tornavam inicialmente disponíveis para vender a sua força de trabalho no mercado haviam se instruído como trabalhadores em práticas de trabalho artesanais e campesinas, as 
quais se caracterizavam por serem processos de trabalho autênticos. Nesse primeiro momento, portanto, não poderia haver subsunção real do trabalho ao capital, já que isto só vai ocorrer quando os fins postos pelo trabalhador deixarem de prevalecer na prática de trabalho, no processo de geração do produto. Dito de outro modo, a subsunção real requer uma restrição progressiva da subjetividade do trabalhador, a subordinação de seus fins aos fins da produção capitalista. De início, pois, apenas poderia haver a subsunção formal do trabalho ao capital, cuja expressão legal é o contrato de trabalho individual. Nos conceitos de Marx, subsunção formal significa que o processo de trabalho enquanto ainda processo de trabalho converte-se em instrumento do processo de valorização.

Daí que de um ponto de vista lógico a subsunção formal seja compatível apenas com a extração da mais-valia absoluta, ou seja, do mais trabalho que é arrancado do trabalhador pelo prolongamento da jornada de trabalho. A extração da mais-valia relativa só pode vir a ocorrer quando o capital passa a revolucionar não apenas as relações entre os diversos trabalhadores, mas também a natureza do trabalho e os modos de trabalhar, por meio da transformação do processo produtivo pela aplicação consciente da ciência e da tecnologia. Agora, os trabalhadores tornam-se materialmente subordinados ao capital, ou seja, tornam-se apêndices de um processo de produção cujo cerne é um sistema de máquinas. Quando isto ocorre, não é mais o trabalhador que interpõe os meios de trabalho entre si mesmo e o objeto de trabalho, mas ele próprio é interposto entre este último e o corpo do capital (o sistema de máquinas). Se antes os modos de trabalhar eram determinados pelo princípio subjetivo, ou seja, pela habilidade e criatividade dos próprios trabalhadores, agora eles estão determinados por um princípio objetivo, ou seja, por uma lógica sistêmica de produção orientada pela acumulação que determina os fins particulares perseguidos pelos trabalhadores. Tem-se, assim, uma primeira negação do processo de trabalho.

De um ponto de vista histórico, a subsunção formal do trabalho ao capital está associada ao período da cooperação e da manufatura, quando então predomina a extração de mais-valia absoluta. Nessas condições de produção, a possibilidade de obtenção de mais-valia relativa é limitada. É só com o advento da grande indústria, quando a subsunção real do trabalho ao capital torna-se efetiva e se generaliza, que passa a predominar o modo relativo de extração de mais-valia em relação ao absoluto, o qual, aliás, nunca desaparece. Quando o capital passa a controlar o modo de trabalhar, consegue obter aumentos da produtividade do trabalho que reduzem o custo de reprodução da força de trabalho, diminuindo, em conseqüência, a necessidade de capital variável para gerar um determinado montante de valor adicionado, o que se traduz, ao final, em um aumento da mais-valia.

É preciso distinguir, como se sabe, dois períodos nos dois séculos de duração da grande indústria: o concorrencial e o monopolista. A gerência científica, o controle dos tempos e dos movimentos (taylorismo), a produção em série e a massificação do produto (fordismo), tudo isso pertence ao modo de produção da grande indústria, mas vem marcar o advento de um novo período caracterizado pela predominância das grandes empresas monopolistas na dinâmica de acumulação capi- 
talista. Sob esses termos não se devem entender apenas novas técnicas de organização da produção, mas procedimentos que moldam e controlam os trabalhadores. Eles estendem, aperfeiçoam e efetivam os sistemas de produção nucleados pelos sistemas de máquinas, os quais levam a um grau mais alto a supressão dos processos de trabalho como tais, com a concomitante constituição de gigantescos macro-sujeitos objetivos capazes de produzir grandes volumes de mercadorias. Vem a ser, pois, a plena efetivação de lógicas de produção objetivas que aparecem como realizações próprias do capital, mas que estão de fato a serviço de sua acumulação acelerada. Os autômatos fabris criados pela primeira revolução industrial transformaram-se, agora, em grandes empresas com muitos níveis hierárquicos e ampla complexidade organizacional. A subsunção real torna-se mais perfeita no chão de fábrica e é, ao mesmo tempo, estendida também para os escritórios, tornando-se inclusive organizacional ${ }^{6}$.

É importante notar que, com o advento do capitalismo monopolista, a geração de superlucro assume uma importância especial na dinâmica da acumulação capitalista. É certo que ela é inerente ao processo da reprodução ampliada. Entretanto, como ressalta Mandel, a manutenção de taxas de lucro acima da média de modo durável por parte dos capitais mais poderosos apenas se torna uma norma quando o capitalismo concorrencial é substituído pelo capitalismo monopolista ${ }^{7}$. Eis que o monopólio - seja ele da terra, da reserva de força de trabalho ou da tecnologia - é que permite a obtenção de superlucros. Estes surgem, pois, de diversas maneiras: da propriedade privada do solo, da vantagem de produtividade detida por certos capitais, do rebaixamento do preço pago pela força de trabalho, da compra de matérias-primas baratas etc. Nas relações entre o centro e a periferia capitalista, eles ocorrem por causa das diferenças entre as taxas de lucros na metrópole e nas colônias, por meio da troca desigual e por meio da cobrança de rendas tecnológicas.

Ora, essa última forma de extração de mais-valia por parte dos grandes capitais assume um caráter decisivo quando a grande indústria vem a ser gradativamente substituída pela pós-grande indústria. Sem que as formas anteriores, relativa e absoluta, deixem de existir, a mais-valia extraordinária, sob a forma de renda tecnológica (oriunda de direitos de reprodução, marca e propriedade intelectual), torna-se, agora, um meio privilegiado de obtenção de ganhos monopolistas.

Segundo Marx, do próprio desenvolvimento da grande indústria deve surgir um terceiro momento do modo de produção capitalista, o qual, empregando aqui o termo sugerido por Fausto, é denominado de pós-grande indústria (Fausto, 2002: 128-140). O autor de $O$ capital escreveu nos Grundrisse de 1857-1858 que “à medida que a grande indústria se desenvolve, a criação da riqueza efetiva torna-se menos dependente do tempo de trabalho e do quantum de trabalho utilizado, do que da força dos agentes [isto é, da ciência e da tecnologia] que são postos em movimento durante o tempo de trabalho" (apud Fausto, 2002: 129). Dito de outro

\footnotetext{
${ }^{6}$ Ver sobre isto Braverman (1974: 293-358).

${ }^{7}$ Ver sobre isto Mandel (1982: 51-54).
} 
modo, o valor já não é mais então, apenas, um quantum de tempo de trabalho, mas se torna influenciado, de modo qualitativo, pelos conhecimentos científicos e tecnológicos que são mobilizados no processo de produção com o concurso necessário dos trabalhadores, durante o tempo de trabalho. A força produtiva social agora se encontra plenamente objetivada, não apenas em máquinas, sistemas de máquinas e empresas sistêmicas, mas também no que Marx denomina de "compreensão da natureza" ou "intelecto geral". Quando isto ocorre, quando os sistemas de produção se tornam mais e mais automatizados por meio do emprego da microinformática que objetiva essa compreensão, muda a função do trabalhador. Para empregar os termos de Marx, pode-se dizer que, então, "o trabalho não aparece mais até o ponto de estar incluido no processo de produção, mas o homem se relaciona antes como guardião e regulador do processo de produção" (apud Fausto, 2002: 130).

$\mathrm{O}$ trabalhador da pós-grande indústria - cujo período histórico se inicia, aproximadamente, no último quartel do século XX - torna-se, pois, guardião e regulador do processo de produção. Ora, isto é crucial, pois vem marcar, segundo Fausto, uma segunda negação do processo de trabalho. Nos limites do capitalismo, o trabalhador continua não determinando os fins de sua atividade, não se torna sujeito de sua própria atividade produtiva, mas deixa de estar inserido como peça no processo de produção. Nessa condição, entretanto, é ainda mantido subordinado de forma real ao capital. Ele é agora chamado a exercer um papel ativo e co-responsável no processo produtivo; em conseqüência, a sua compreensão maior ou menor do processo tem de estar a serviço desse processo. Assim, se ele deixa de estar intercalado, mesmo se é liberto materialmente do processo de produção ${ }^{8}$, o sistema de produção, no qual se encontram objetivados conhecimentos científicos e tecnológicos extremamente avançados, passa a exigir dele um comprometimento subjetivo, de atenção permanente, um envolvimento intelectual com o seu adequado funcionamento. A pós-grande indústria é caracterizada, por isso, pela subsunção formal, intelectual e societária do trabalho ao capital.

$\mathrm{Na}$ pós-grande indústria, a matéria por excelência do capital - ou seja, a matéria principal que dá suporte às suas formas - não é mais a máquina, o sistema de máquina, a fábrica ou a fazenda em sua materialidade corpórea. A matéria privilegiada do capital, aquela em que recai o grande investimento porque aí está a fronteira da acumulação e a fonte dinâmica da geração de lucros, vem a ser agora o próprio conhecimento científico e tecnológico. Eis que assim o capital não se associa, sobretudo, aos ativos tangíveis, mas aos ativos intangíveis ou imateriais objetos de um novo qüiproquó fetichista. É por isso que o emprego de expressões como "capital conhecimento", "capital humano" e "capital intelectual", que con-

\footnotetext{
${ }^{8}$ Coriat distingue, nesse aspecto, as indústrias de processo contínuo, em que os trabalhadores, agora polivalentes, atuam de fato como supervisores e controladores externos do processo de produção, das indústrias de produção em série, utilizadoras intensivas de robôs, em que os trabalhadores continuam submetidos ao ritmo de produção. Nesse caso, ele diz que os trabalhadores atuam como acompanhantes próximos do processo de produção. Isto mostra que as novas forças produtivas, pelo menos dentro da disciplina do capital, apresentam pouco potencial de liberação. Ver Coriat (1988: 111-116).
} 
funde a forma e a matéria do capital, se generaliza. É por isso que os chamados direitos de propriedade intelectual, assim como as rendas tecnológicas, assumem importância crescente no capitalismo contemporâneo (Perelman, 2003). É por isso, ainda, que os sistemas de patentes alargam sua função na produção, seja integrando novas áreas, seja estabelecendo direitos sobre as idéias em si mesmas, seja aumentando o período de proteção (Andersen, 2003: 36). Defende-se, inclusive, que qualquer "new idea of doing business" poderia ser agora patenteada, desde que "útil e concreta"!

Ciência e tecnologia são bens sociais e públicos, mas se tornam objetos de investimento capitalista, transformando-se em fonte de renda de monopólio. Por outro lado, a produção de tecnologias torna-se uma atividade econômica mais e mais separada da produção propriamente dita de mercadorias. Assim, uma parte importante do capital produtivo mescla-se com o capital financeiro - o qual foi desregulado nas últimas três décadas do século XX. Como a desregulamentação financeira após 1980 mostrou-se condição para a reestruturação da dominação do capital, na forma da pós-grande indústria, surge a percepção de que o neoliberalismo vem a ser o domínio do capital financeiro.

\section{RAÍZES DAS FORMAS DE LIBERALISMO}

Wallerstein aponta que o pensamento liberal sempre foi contraditório: afirmava que todos os indivíduos e todos os povos têm direitos iguais, mas dava suporte a um sistema caracterizado, seja no nível nacional seja no nível internacional, por uma desigualdade gritante (Wallerstein, 2002: 167). O liberalismo, entretanto, não enxergava aí contradição alguma: ele via apenas diferenças entre indivíduos que espelhavam e estimulavam a livre competição. Tais diferenças são, pois, o resultado necessário de um processo social progressivo baseado na livre iniciativa das pessoas. Daí - como também aponta Wallerstein - que tenha sempre posto ênfase no processo. Eis que a economia de mercado - afirmava - origina uma sociedade dinâmica, que, no curto prazo, premia uns - ou seja, aqueles que trabalham mais, poupam mais, têm mais competência etc. - em relação a outros e que, no longo prazo, premia a todos porque a grande maioria melhora. Por isso, afirmava, o aperfeiçoamento racional do sistema por meio da engenharia social, que opera aos poucos, corrige as distorções e abre novas oportunidades, gera, pelo menos como tendência, uma sociedade justa.

Eis, porém, que isto não está mais no horizonte. Eis, ademais, que a negação dessa premissa assinala a negação do próprio liberalismo como tal. Para compreender essa e outras antinomias tão características do capitalismo é preciso começar por compreender o liberalismo em geral e, em particular, em sua forma clássica.

A contradição do pensamento liberal está enraizada no próprio capitalismo. 
Assim como o Estado ${ }^{9}$, esse pensamento político deve ser derivado da contradição entre a aparência e a essência desse modo de produção. Dito de outro modo, ele decorre da contradição entre a circulação mercantil, superfície em que os homens aparecem como indivíduos, iguais possuidores de propriedade, livres e racionais, e a sua essência, em que esses homens são membros de classes sociais, inerentemente desiguais e que atuam como suportes de relações sociais que se reproduzem cega e infinitamente. $\mathrm{Na}$ aparência da circulação, trabalhadores e capitalistas trocam equivalentes, mas abaixo dessa superfície, encontra-se o contrário; a reprodução reiterada da relação social de produção mostra o fundo do sistema, ou seja, que o trabalho morto se nutre do trabalho vivo e que aquela relação era verdadeiramente uma relação entre desiguais, uma relação por meio da qual a classe dos capitalistas se apropria da riqueza produzida pela classe dos trabalhadores. Num trecho bem conhecido, Marx diz:

"A esfera da circulação ou do intercâmbio de mercadorias, dentro de cujos limites se movimentam compra e venda de força de trabalho, era de fato um verdadeiro éden dos direitos naturais do homem. O que aqui reina é unicamente Liberdade, Igualdade, Propriedade e Bentham. (...) Ao sair dessa esfera da circulação simples ou da troca de mercadorias, da qual o livre-cambista vulgaris extrai concepções, conceitos e critérios para seu juízo sobre a sociedade do capital e do trabalho assalariado, já se transforma, assim parece, em algo a fisionomia de nosso dramatis personae. $\mathrm{O}$ antigo possuidor de dinheiro marcha adiante como capitalista, segue-o o possuidor de força de trabalho como seu trabalhador (...)" (Marx, 1983a: 145).

É apenas fiando-se nessa compreensão superficial do capitalismo, em que este é tomado como um sistema constituído essencialmente por mercados, que um autor como Adam Smith pode estabelecer um dos argumentos mais fundamentais do liberalismo econômico, a saber, o argumento da mão invisível. Eis que não se tem aqui apenas uma concepção que se refere ao caráter homeostático de um funcionamento descentralizado, baseado em decisões individuais localmente informadas, mas também uma afirmação sobre o caráter espontaneamente beneficente do sistema econômico capitalista. A mão invisível afiança que há uma coincidência do interesse individual com o interesse geral e se constitui, por isso, numa justificativa para restringir ao máximo a ação do Estado (este deve prover, apenas, infra-estrutura, defesa, segurança e justiça), deixando plena liberdade de ação aos interesses privados. É claro que o liberalismo clássico atém-se ao momento formal de relação entre o trabalho assalariado e o capital.

O liberalismo clássico caracteriza-se pela defesa da liberdade de comércio, do

\footnotetext{
${ }^{9}$ Sobre a derivação do Estado a partir de O capital, consultar o texto "Sobre o Estado", de Ruy Fausto (Fausto, 1987: 287-329).
} 
mercado livre - especialmente da compra e venda de força de trabalho - e da estabilidade do padrão monetário. É, pois, ideologia que afirma e acentua o aspecto positivo e superficial do modo de produção capitalista (o seu primeiro momento) para bloquear uma compreensão profunda de sua natureza (ou de seu segundo momento). "Ele nega o segundo momento no nível das idéias, exatamente para que ele seja posto no nivel da base 'material'." Dito de outro modo, como ideologia, ele "guarda apenas o momento da igualdade dos contratantes negando a desigualdade das classes, para que, contraditoriamente, a igualdade dos contratantes seja negada e a desigualdade das classes seja posta" (Fausto, 1987: 299-300). Assim como o Estado, o pensamento político ideológico é imprescindível para a conservação do capitalismo; ambos, o primeiro no plano da ação coletiva concentrada e da violência preventiva e repressiva e o segundo no plano do bloqueio da formação da consciência crítica, têm como função conservar a identidade de uma totalidade social contraditória.

Justamente porque são forças de conservação, o Estado capitalista e a ideologia liberal têm de acompanhar o próprio desenvolvimento contraditório do modo de produção capitalista, adaptando-se às mudanças mais profundas que ocorrem nas forças produtivas e, assim, nas relações de produção e na correlação de força entre as classes. Fausto argumenta que as leis de desenvolvimento do capitalismo (tendência à queda da taxa de lucro, por exemplo) e as lutas sociais e históricas da classe trabalhadora impuseram novas prioridades ao Estado capitalista, impondo mudanças que se refletiram também no pensamento liberal. Diante dos desafios do capitalismo monopolista e das perturbações e ameaças representadas pelo agravamento do conflito social, o Estado teve de começar a atuar, especialmente no século XX, como uma força compensatória e de balanceamento do sistema. É assim que o liberalismo clássico veio a ser modificado pelo liberalismo social, que se caracterizou, sobretudo, pela defesa prudente da regulação estatal na atividade econômica.

É certo que a intervenção do Estado é uma constante na história do capitalis$\mathrm{mo}^{10}$. A intervenção defendida pelo liberalismo social e praticada pelo Estado regulador, porém, destaca-se por ser equilibradora, ou melhor, re-equilibradora. Ela concerne à regulamentação da concorrência (para dificultar a permanência no tempo dos lucros extraordinários), ao balanceamento das forças entre capitalistas e trabalhadores (para moderar os conflitos de classe e redistribuir os benefícios do crescimento), à suplementação das funções econômicas exercidas pelos capitais privados (o Estado transforma-se num agente econômico empreendedor). O princípio norteador do liberalismo social é que o mercado auto-regulável, deixado a si mesmo, é autodestrutivo e que, por isso, ele requer a regulação do Estado. O re-

\footnotetext{
${ }^{10}$ Ninguém melhor do que Polanyi criticou a idéia de que o capitalismo prescinde da intervenção estatal. "A história econômica mostra" - disse - "que a emergência de mercados nacionais não foi, de forma alguma, o resultado da emancipação gradual e espontânea da esfera econômica do controle governamental. Pelo contrário, o mercado foi a conseqüência de uma intervenção consciente, e às vezes violenta, por parte do governo que impôs à sociedade a organização do mercado, por finalidades nãoeconômicas" (Polanyi, 1980: 244).
} 
sultado histórico dessa forma de intervenção foi a constituição do que acabou sendo chamado de Estado de bem-estar social. Nos países da periferia, em que faltavam as condições materiais de desenvolvimento para chegar rapidamente ao amortecimento das lutas de classes, o Estado tornou-se desenvolvimentista.

O liberalismo social surge historicamente quando a aparência do modo de produção é desmentida na prática social, quando se torna perigoso para os capitalistas aferrarem-se à mera forma da relação social de produção, quando a conservação do sistema torna-se ameaçada pela radicalidade das lutas sociais e pelas crises econômicas que as tornam ainda mais radicais. Então, a ideologia não pode mais se sustentar apenas na aparência da relação social; ela precisa agora, de certo modo, ter em conta a própria essência dessa relação. A fórmula que emerge consiste em apresentar a essência, não como essência, mas como diferença: há duas forças sociais em confronto e elas são distintas; uma delas tem menos poder e mais potência; uma delas consome insuficientemente e a outra poupa demais; uma delas não encontra ocupação e a outra não está criando ocupações em número suficiente para que seja mantida a paz social. Nessa perspectiva, afigura-se que cabe ao Estado atuar como força equilibradora; a política econômica keynesiana e a política social-democrática, a partir dos anos 40 do século XX, podem então passar a ocupar o centro do cenário. Não é mais, pois, a identidade, mas vem a ser a diferença que oculta a contradição.

O liberalismo social veio a ser a ideologia apropriada ao período da grande indústria quando sobrevieram as crises do final do século XIX e quando o capitalismo se tornou monopolista. Na história do pensamento econômico, entretanto, ele aparece já nas teses de John Stuart Mill. Segundo esse autor, os fenômenos da produção estão subordinados às leis naturais, caracterizadas por um determinismo que não pode ser modificado pelo homem. A repartição, entretanto, pode ser objeto de legislação humana e esta pode promover uma melhor conciliação do interesse geral com os interesses privados. A essência do capitalismo não aparece nessa visão política como exploração, mas como má repartição da renda e da riqueza, como diferença e desigualdade que o reformismo pode modificar. "A sociedade" - disse Mill - pode submeter a distribuição da riqueza a quaisquer normas que lhe parecem melhores" (Stuart Mill, 1983: 182).

De um ponto de vista lógico, o liberalismo social corresponde a um reconhecimento mistificado da subordinação real do trabalho ao capital. Com a grande indústria - note-se, de início -, as forças produtivas sociais do trabalho aparecem como força do capital, de modo tal que a contribuição dos trabalhadores passa a afigurar apenas como força coletiva suplementar. Marx mesmo enfatizou que, por isso, o modo de produção se torna especificamente capitalista. Não só porque a subordinação torna-se material - a máquina é matéria adequada à forma capital e a força de trabalho massificada torna-se cada vez mais adequada à exploração do capital -, mas também por causa da figura real do modo de produção.

"As forças produtivas sociais do trabalho (...) esse desenvolvimento da força produtiva do trabalho objetivado, por oposição ao trabalho 
mais ou menos isolado dos indivíduos dispersos etc., e com ele a aplicação da ciência - esse produto geral do desenvolvimento social - ao processo imediato de produção; tudo isso se apresenta como força produtiva do capital, não como força produtiva do trabalho; (...) A mistificação implícita na relação capitalista em geral desenvolve-se agora muito mais do que podia ou teria podido se desenvolver no caso da subsunção puramente formal do trabalho ao capital. Ademais, é aqui que o significado histórico da produção capitalista surge pela primeira vez de maneira cabal (de maneira específica), precisamente por força da transformação do processo imediato de produção e do desenvolvimento das forças produtivas sociais do trabalho" (Marx, 1978: 55-56).

É a realidade da grande indústria monopolista, entretanto, que mina a aparência isonômica da sociedade. De um lado, os capitais, investidos em corpos mecânicos colossais, ou seja, em fábricas que produzem em grande escala, figuram assim como grandes potências produtivas; de outro, os trabalhadores, os verdadeiros produtores, aparecem como massas que vivem na pobreza e na insegurança. As lutas sociais tornam-se mais ameaçadoras. Isto suscita mudanças. A forma do contrato de trabalho deixa de ser individual para se transformar em contrato coletivo, intermediado de algum modo pelo Estado. Essa mudança reflete, no plano jurídico, a negação da igualdade das partes assumida na relação meramente formal entre capitalistas e trabalhadores assalariados. Em razão, pois, das próprias características da subsunção material, a essência do modo de produção aparece até certo ponto e, por isso mesmo, deve aparecer de um modo atenuado, não como contradição, mas como relação de uma parte forte, o capital, com uma parte fraca, o trabalho, que requer inclusive a intervenção compensatória do Estado.

O otimismo liberal clássico transforma-se no precavido liberalismo social: a mão invisível do mercado - reconhece-se - precisa até certo ponto do braço poderoso do Estado. Entretanto, alguns economistas liberais (ditos também libertários!), já nos anos 30 e principalmente no pós-guerra, começaram a temer as conseqüências dos arranjos econômicos, sociais e políticos, os quais legitimamente podem ser chamados também de social-democratas; segundo eles, estes arranjos estavam minando o capitalismo. A essência do argumento de Hayek, por exemplo, não incide em identificar a produção capitalista com uma ordem natural que se impõe por determinação de leis férreas, mas consiste em dizer que essa ordem vem a ser moral, que foi constituída de modo espontâneo, mas que é politicamente frágil, e que, por isso, deve ser preservada intencionalmente, já que só ela é consistente com a liberdade do empreendimento privado. Ora, com a crise dos anos 70 - queda da taxa de lucro, estagflação etc. - o neoliberalismo sai dos pequenos círculos de intelectuais de direita para ganhar o comando da política mundial ${ }^{11}$.

\footnotetext{
${ }^{11}$ Essa história é contada como uma grande conquista, do ponto de vista neoliberal, por Yergin e Stanislaw (2002).
} 
Assim, acaba aos poucos a política de conciliação relativa oferecida pelo capital ao trabalho assalariado.

\section{ENFIM, O NEOLIBERALISMO}

O Estado para o liberalismo clássico deve ser economicamente passivo; para o liberalismo social, ele deve regular ativamente a atividade econômica; já para o neoliberalismo, ele deve ser um agente econômico ativamente passivo. No dizer de um autor dessa corrente de pensamento (Louis Baudin), "o Estado deve ser um soberano que prepara sua própria abdicação" (apud Hugon, 1972: 152). Deve ser, pois, um Estado que cria ativamente as condições para a acumulação de capital, que protege os monopólios das crises econômicas, que enfraquece o poder dos sindicatos de trabalhadores assalariados, que despoja os trabalhadores da seguridade social, que privatiza as empresas públicas, que transforma a oferta de bens públicos (como as estradas, os portos etc.) em serviços mercantis, que não só levanta, enfim, os obstáculos ao funcionamento dos mercados e das empresas, mas é capaz de criar as condições para que estas últimas operem de modo lucrativo.

Não se entende o neoliberalismo se este é compreendido como uma reversão ao liberalismo clássico - ou como renascimento deste último. Pois, nessa última doutrina, o Estado nunca pode comparecer como agente econômico. Ora, sob a cobertura ideológica do liberalismo social e diante de necessidades históricas concretas postas pelo desenvolvimento do modo de produção capitalista, o Estado acabou assumindo, diretamente, funções econômicas complementares às das empresas privadas. Ele mesmo, por exemplo, instituiu bancos de investimento e se associou, por esse meio, ao capital privado. Ele mesmo passou a atuar como proprietário de empresas, encarregando-se da produção em setores de base ou estratégicos, com o fim de completar a estrutura industrial das nações. Ele passou a regular o fluxo de dinheiro e do crédito por meio de bancos centrais.

O neoliberalismo não vem a ser a doutrina do Estado mínimo ${ }^{12}$. Ele não isenta o Estado das atividades de complementação econômica. Ao contrário, para ele, o Estado deve preencher ativamente os vazios da malha produtiva e financeira, mas deve fazê-lo não por meio de empresas próprias, e sim, preferencialmente, adjudicando as atividades econômicas complementares, por meio de contratos de gestão, às empresas privadas. Entretanto, quando isto não é possível, como no caso da gestão monetária, o neoliberalismo propugna pela privatização funcional (ou seja, por uma gestão que é colocada nas mãos de uma elite tecnocrática que atua na esfera pública, de fato, como preposto do setor privado). Com o neoliberalismo, o

\footnotetext{
12 Uma citação do presidente do Banco Mundial, James D. Wolfensohn, é bem ilustrativa. Segundo ele, "longe de fornecer evidência para a defesa de um Estado mínimo, as experiências bem sucedidas de desenvolvimento mostraram que este requer um Estado efetivo, que possa ter um papel facilitador, catalítico, encorajador e complementador das atividades dos indivíduos e dos negócios privados" (apud Hildyard, 1997: 5).
} 
Estado torna-se diretamente comprometido com a recuperação e manutenção da taxa de lucro num nível adequado para a continuidade do capitalismo.

O neoliberalismo - foi dito na introdução deste trabalho - vem a ser a segunda negação do liberalismo. Se o liberalismo social representa, de certo modo, uma consciência neutralizada da subsunção do trabalho sob o capital, portanto, da essência oculta do capitalismo - e, nesse sentido, vem a ser uma primeira negação -, o neoliberalismo vem expressar o reconhecimento da contradição entre o trabalho e o capital, ainda que também de modo mistificado. A contradição é assumida como disposição social cujo desenvolvimento conflituoso deve ser necessariamente bloqueado e cuja natureza deve ser contrariada por meio de uma unificação de classe. Agora, é a própria contradição que tem de ser objetivamente neutralizada.

Nas condições da pós-grande indústria, o capital tem de manter a dominação do trabalho de novas maneiras. Então, por um lado, o neoliberalismo promove um regime de social darwinismo em todas as esferas da sociedade. Por outro, requer um comportamento cooperativo de todas as pessoas da população. Em síntese: ele busca uma corrida de ratos cooperativa! Na presença de crescente anomia, corrupção e violência, quando muitas dificuldades emergem na superfície da sociedade, ele propugna sempre pelo reforço do caráter policial e punitivo do poder da propriedade privada e do Estado.

De certo modo, pois, pode-se dizer que, com o advento da pós-grande indústria, o capitalismo tem de aparecer como capitalismo, quase francamente como um sistema baseado em dominação de classe. Ele surge como um sistema de relações sociais assimétricas e polarizadas e que gera inerentemente exclusão, mas com o qual é preciso se conformar já que ele vem a ser o único que supostamente permite a liberdade e a democracia representativa. Eis que esse sistema para os atuais defensores da propriedade privada dos meios de produção está constantemente ameaçado pela usurpação dos rendimentos dos proprietários privados pelos sindicatos, pelos governos corruptos, pela política tributária criada por legisladores demagogos, pela revolta dos derrotados etc. A contradição entre o trabalho e o capital não é, pois, ocultada; ela aparece de certo modo, mas é apresentada como uma espécie de motoperpétuo concorrencial necessário à boa sociedade, para o qual não há - diz o neoliberalismo - alternativa.

É preciso ver que, diferentemente do que ocorria na grande indústria, na pósgrande indústria, a força produtiva social do trabalho não aparece mais como força produtiva do capital, mas sim como atributo da atividade humana coletiva e social. Porém, essa força produtiva não se apresenta como resultado que decorre de modo imediato da atividade do trabalhador, mas como algo que é mediado por ele e que advém do intelecto geral:

“(...) Nessa transformação não é nem o trabalho imediato que o homem executa, nem o tempo que ele trabalha, mas a apropriação da sua própria força produtiva universal, sua compreensão da natureza e a sua dominação dela por meio de sua existência como corpo social - em uma 
palavra, [é] o desenvolvimento do indíviduo social que aparece como o grande pilar da produção e da riqueza” (apud Fausto, 1987: 131).

O velho fetiche do capital, ou seja, a identificação da forma da relação de capital com a máquina, o sistema de máquina e com a materialidade da fábrica, perde força na sociedade. É certo que o capital pode se apossar de conhecimentos aplicáveis à produção, por exemplo, por meio de patentes, mas as patentes se mostram, sem engano, como forma do capital cuja existência depende de uma proteção jurídica direta, sendo consideradas, justamente por isso, direitos de propriedade intelectual. Por outro lado, a totalidade complexa constituída pela informação, pelo conhecimento científico e tecnológico ganha expressão como força produtiva. Eis que essa inteligência coletiva é uma força que não pode ser apropriada como um todo, existe necessariamente de modo descentralizado, forma uma rede extremamente complicada e está em permanente processo de reconstrução.

Marx - vale lembrar - chama essa capacidade produtiva de "compreensão da natureza", distinguindo-a como fonte por excelência da produtividade do homem social no estágio avançado da produção desenvolvida pelo capitalismo. Ora, essa força produtiva é tanto fonte da riqueza material e imaterial, quanto, juntamente com o trabalho social, do valor e da mais-valia. Sendo algo que tem uma existência imaterial e que existe de modo espalhado na sociedade, aparece, entretanto, junto do trabalho como realização histórica do homem em geral, não mais como atribuição inerente ao capital. Eis que isto não impede, porém, que a economia vulgar venha chamá-lo de "capital humano" e "capital intelectual”. E o fazem porque os capitalistas, como classe e como indivíduos, continuam proprietários dos meios de produção em geral e, portanto, das condições do trabalho, mesmo quando elas se encontram na cabeça dos trabalhadores. Eis que o enigma dessas duas expressões se revela quando se percebe que a forma da relação de capital aparece do lado da classe proprietária, mas que a matéria sobre a qual essa forma incide surge como propriedade inerente à força produtiva da classe não possuidora.

Note-se em adição, por um lado, que não há mais agora adequação entre a matéria que dá suporte à forma do capital, ou seja, o conhecimento, e esta mesma forma, e que, por outro lado, a força de trabalho que mobiliza o conhecimento e que faz com que a produção não pare, que empenha para tanto a própria subjetividade no processo de produção, não é mais perfeitamente apropriada à exploração do capital. É por isso mesmo que a dominação do capital, longe de se abrandar, tem de se tornar intransigente e totalizadora, estendendo-se não apenas sobre o tempo de trabalho, mas também para fora desse tempo, para a vida do trabalhador como um todo. Este último tem, então, de se tornar um trabalhador de corpo e alma da empresa capitalista. Mas, desse modo, o capital, que agora perdeu grande parte de sua aparência como força produtiva material, revela a sua essência, pois se afigura como uma forma de sugar a riqueza gerada pela atividade social - uma atividade que une indissoluvelmente o trabalho social com o saber sobre os processos de produção (saber este que se transforma, mais e mais, de instrumento de apropriação da natureza em capacidade de reorganização compreensiva da natureza). 
O neoliberalismo é uma forma política tendencialmente totalitária em que a unidade social é imposta por uma ideologia abrangente (educação, alinhamento "voluntário", propaganda, espetáculo etc.) sempre que possível, mas pela força (administração do medo, vigilância do grande irmão, ações militares, terror de Estado etc.) sempre que necessário.

Conforme o neoliberalismo, o Estado deve atuar, sem qualquer vergonha, como agente que promove os interesses capitalistas. Representa a opção conservadora diante do esgotamento histórico tanto do liberalismo social quanto dos socialismos centrados na ação do Estado. Vem a ser a ideologia que defende o sistema capitalista quando a relação de capital se tornou potencialmente supérflua e quando a autogestão dos processos de produção pelos próprios trabalhadores começa a se mostrar como uma opção efetiva, mais produtiva inclusive do que a opção gerencial, e que permite um maior grau de auto-realização. A pós-grande indústria, diz Fausto, pode ser caracterizada como "negação" do capitalismo no interior do capitalismo ${ }^{13}$. Já um autor como Melman pode escrever, com otimismo exagerado quando se tem em mente o momento histórico atual, mas também com certa sabedoria, que "o capitalismo está em processo de transformação, caminhando para uma economia baseada na democracia no local de trabalho" (Melman, 2001: 585).

Enquanto isso não ocorre, acentua-se cada vez mais a irracionalidade social e ecológica do capitalismo. Tem razão, pois, Bensaïd quando afirma com base no mesmo texto dos Grundrisse antes mencionado que a humanidade está diante de uma encruzilhada:

“Tal como Marx previu em seus Manuscritos de 1857-1858, 'o roubo do tempo de trabalho de outrem sobre o qual repousa a riqueza atual' aparece então como "uma base miserável', porque "quando o trabalho deixa de ser a grande fonte da riqueza sob a forma imediata, o tempo de trabalho deixa de ser necessariamente a sua medida e, por conseguinte, o valor de troca deixa de ser a medida do valor de uso'. A exacerbação dessa contradição constitutiva do processo de acumulação capitalista está na raiz do desregramento do mundo, de sua irracionalidade crescente, dos danos sociais e ecológicos" (Bensaïd, 2003: 33).

\section{REFERÊNCIAS BIBLIOGRÁFICAS}

ANDERSEN, B. (2003) “The neglected patent controversies in the twenty first century". Revista Brasileira de Inovação, vol. 2 (1), jan./jun., pp. 35-78.

\footnotetext{
${ }^{13}$ Um livro que apreende com argúcia a mudança recente do capitalismo, ainda que no modo do entendimento, vem a ser o Império de Hardt e Negri (2000). Em conseqüência, a crítica deles não vai suficientemente longe porque, no fundo, apreendem a mercadoria só como valor de uso e o trabalho só como trabalho concreto (Prado, 2003).
} 
ANDERSON, P. (2003) “Idéias e ação política na mudança histórica”. Margem Esquerda, vol. 1, pp. 79-92. BENSAÏD, D. (2003) Um monde à changer - mouvements et stratégies. Paris: Textuel.

BEYNON, H. (2003) “O sindicalismo tem futuro no século XXI?”. In: Além da Fábrica - trabalhadores, sindicatos e a nova questão social; org.: M. A. Santana e J. R. Ramalho. São Paulo: Boitempo.

BRAVERMAN, H. (1974) Labor and Monopoly Capital - The Degradation of Work in the Twentieth Century. New York: Monthly Review Press.

CORIAT, B. (1988) A revolução dos robôs - O impacto socioeconômico da automação. São Paulo: Busca Vida.

DOBB, M. (1983) A evolução do capitalismo. São Paulo: Abril Cultural.

DUMÉNIL, G. e LÉVY, D. (2003) Économie marxiste du capitalisme. Paris: La Decouverte.

FAUSTO, R. (2002) Marx: Lógica e Política - Investigações para uma reconstrução do sentido da dialética. Tomo II: São Paulo: Brasiliense, 1987; tomo III: São Paulo: Editora 34, 2002.

HARDT, M. e NEGRI, A. (2000) Empire. Cambridge: Harvard University Press.

HILDYARD, N. (1997) The World Bank and the State: a Recipe for Change? Londres: Bretton Woods Project.

HUGON, P. (1972) História das doutrinas econômicas. São Paulo: Atlas.

MANDEL, E. (1982) O capitalismo tardio. São Paulo: Abril Cultural.

MARX, K. (1978) O capital - livro I, capitulo VI (Inédito). São Paulo: Ciências Humanas.

MARX, K. (1983) O capital - Crítica da Economia Política. São Paulo: Abril Cultural, vol. I, tomo 1 (a) e tomo 2 (b).

MELMAN, S. (2001) After Capitalism. New York: Randon House.

PERELMAN, M. (2003) “The Political Economy of Intellectual Property". Monthly Review, janeiro.

POLANYI, K. (1980) A grande transformação. Rio de Janeiro: Campus.

PRADO, E. F. S. (2003) "Pós-grande indústria: trabalho imaterial e fetichismo". In: Crítica Marxista, vol. 17, p. 109-130.

ROSDOLSKY, R. (2001) Gênese e estrutura de O capital de Karl Marx. São Paulo: EDUERJ: Contraponto. STUART MILL, J. (1983) Princípios de economia política - com algumas aplicações à filosofia social. São Paulo: Abril Cultural.

WALLERSTEIN, I. (2002) Após o liberalismo - em busca da reconstrução do mundo. Rio de Janeiro: Vozes. YERGIN, D. e STANISLAW, J. (2002) The Commanding Heights - The Battle for the World Economy. New York: Touchstone. 